failure to take an intelligent interest in the study of his own activities? We know that the most serious conflicts which arise in the life of any person are not directly due to disorders in the field of consciousness, and this is equally true for the individual and the nation. Whenever human beings or nations create an imaginary world in which they attempt to live until some disaster necessitates a sudden readjustment of the fictitious environment to meet the conditions of actual facts, a crisis of major importance is precipitated. From the dawn of history to the present time the thoughts, words and deeds of an imaginary human race have been written for us by philosophers, poets and historians. Conceptions of religion and patriotism, ideals of social justice, and aspirations for the future have been associated in our minds with the imaginary emotional reactions of an idealized race of beings, and now we have been rudely awakened to the necessity of studying men as they live, move and have their being.

\section{REMOVAL OF TONSILS AND ADENOIDS IN DIPHTHERIA CARRIERS *}

\section{S. A. FRIEDBERG, M.D. CHICAGO}

The importance of promptly ridding the diphtheria carrier of diphtheria bacilli needs no emphasis. Not only may the carrier spread diphtheria, but in children the loss of school days and the difficulties of quarantine are serious matters. In hospitals for infectious diseases, the presence of otherwise healthy patients for a prolonged period, with occupation of beds needed for those actually sick, and with the constant liability to cross infection, is, to say the least, burdensome. In this hospital it has been found, as will be reported soon in detail, that dry and finely powdered kaolin properly applied materially shortens the necessary stay of patients in the hospital. In the course of observation, however, several instances have been met in which the local application of kaolin ${ }^{1}$ seemed to be without any effect on the bacilli. In view of the prompt disappearance of the bacilli in these cases after tonsillectomy and removal of adenoids, it seemed advisable to make a brief report of the results.

CASE 1.-Boy, aged 13, onset June 4, admitted June 8; 20,000 units antitoxin, a case of moderately severe pharyngeal diphtheria. Kaolin was applied daily from June $14^{*}$ to July 30 but without effect. July 31, the tonsils and a small amount of adenoid tissue were removed. The tonsils were large and irregular, with large crypts. The cultures became negative immediately following the operation, after having been positive for fifty-seven days before.

CASE 2.-Girl, aged 14, onset September 6, admitted September $9 ; 40,000$ units antitoxin, a case of severe pharyngeal diphtheria. The bacilli persisted in spite of the use of kaolin until October 21 , and then the tonsils, which were large and with deep crypts, were removed. The cultures became immediately negative.

CASE 3.-Girl, aged $81 / 2$ years, onset October 20 , admitted October $26 ; 20,000$ units antitoxin, a severe case of pharyngeal diphtheria. The bacilli persisted to November 27 , and then the tonsils, which were large and ragged, and a moderate amount of adenoid tissue were removed. The cultures became promptly negative for diphtheria bacilli.

* From the Durand Hospital of the Memorial Institute for Infectious Diseases.
1. Hektoen, L., and Rappaport, B.: The Use of Kaolin to Remove 1. Hektoen, L., and Rappaport, B.: The Use of Kaolin to Remove
Bacteria from the Throat and Nose, The Journal A. M. A., June 12, 1915 , p. 1985.
CASE 4.-Woman, aged 21, onset November 15, admitted November $17 ; 25,000$ units antitoxin, a case of moderately severe pharyngeal diphtheria. The cultures from the throat and nose continuing positive, the tonsils were removed, December 8 , the right being large, irregular, with many crypts; the left small and submerged. The cultures were positive for two days after the operation, and thereafter negative.

CASE 5.-Girl, aged 11 years, onset November 7, admitted November $9 ; 20,000$ units antitoxin, a moderately severe case of pharyngeal diphtheria. The cultures from the nose being positive, the tonsils, which were moderately enlarged and irregular, with numerous crypts, were removed, December 8 , whereupon the cultures became negative.

Case 6.-Boy, aged $81 / 2$ years, admitted as a carrier without symptoms of intoxication and treated with kaolin from November 7 to December 13 ; then the moderately enlarged and irregular tonsils were removed (Dr. E. McGinnis), the cultures immediately becoming negative.

In none of these patients did the operation have any different general effects than it has ordinarily. In all of the patients the Schick test gave negative results just before the operation. Six successive negative cultures were required before the patients were discharged.

The results obtained in this series indicate clearly that in persistent carriers it may be necessary to remove the tonsils and adenoid tissue if it is desired to terminate promptly the carrier condition.

The bacteriologic examination should be made with care, as it is well known that applications of medicinal agents may destroy the bacilli on the surface while leaving unaffected those in the crypts of the tonsils and the folds of the adenoid tissue.

As to the time the operation should be performed, it is perhaps advisable to wait from two to three weeks after the clinical recovery of the patient. In the case of the chronic carrier, no time limit is of course necessary.

\section{CONGENITAL ATRESIA OF THE ESOPHAGUS \\ REPORT OF A CASE * \\ EVERETT O. JONES, M.D. AND \\ JOHN B. MANNING, M.D. SEATTLE}

Owing to the comparative infrequency of this condition, the following case is considered of sufficient interest to report:

History.-Soon after the birth of a full term girl, born in normal labor with a birth weight of 7 pounds, it was noticed that mucus ran from the baby's nose and mouth, and that apparently she could not swallow water given her and regurgitation through the month and nose occurred, associated with severe coughing and an extreme blueness of the skin. During these three days before the baby came under our care, there were apparently numerous meconium movements.

Physical Examination.-The baby was rather poorly norished but fairly well developed. The skin was dry from the loss of water but not yet tough. There was a slight general cyanosis, especially of the finger tips. There was a more or less constant discharge of mucus from the nose and mouth, both stringy and containing air. There was a unilateral harelip and a complete cleft palate of the same side.

* From the Children's Orthopedic Hospital.

* Read before the King County Medical Society, October, 1915. 